\title{
Spanish-Language Cross-Cultural Validation of the Bimanual Fine Motor Function Classification System, BFMF 2
}

\author{
Rocío Palomo Carrión* \\ Physiotherapy Department, CEU San Pablo University, Spain
}

*Corresponding author: Rocío Palomo Carrión PhD, Physiotherapy Department,

CEU San Pablo University, Montepríncipe Campus, Madrid, Spain.

\author{
Received Date: August 24, 2019 \\ Published Date: August 26, 2019
}

\section{Abstract}

Introduction: Independent performance in infantile cerebral palsy is affected in daily life by the alteration in fine motor function and gross motor function. The function of the hand, expressed by the fine motor function, is essential to manipulate objects in daily life. The objective of this study was to translate and transculturally validate the bimanual fine motor function classification system, BFMF 2 for the Spanish population, as an instrument for the classification of bimanual fine motor function in children aged 3 to 18 years diagnosed with infantile cerebral palsy.

Material and Methods: The BFMF 2 consists of 5 levels of fine manual skill classification. For the execution of the Spanish version, a specific methodology of translation and back translation was used, reviewed by a group of experts in the upper extremity and approval of the Spanish version by the authors.

Results: the 5 levels of the scale were considered equivalent with the original version, being $100 \%$ literal, which gives a reliability of use at the scale for the Spanish population.

Conclusion: Having the Spanish version of this bimanual fine motor function classification system for infant cerebral palsy in the school stage allows the functioning of both hands to be defined in a more exhaustive way

Key words: Infantile cerebral palsy; Bimanual fine motor function; Transcultural adaptation

\section{Introduction}

In developed countries, the incidence of infantile cerebral palsy (ICP) is around 2-3 cases per 1000 births [1] and is the most often cause of neuromotor disability in childhood. It is defined as a group of disorders of posture and movement [2] that includes another series of associated problems: spasticity, activation of agonistantagonist muscles, muscle weakness and limited range of motion, which affect fine motor function and other additional problems, such as learning deficit, epilepsy, visual impairment, hydrocephalus, deficits in language, perception and behavior are also common and often coexist affecting activity and participation in society [3].

Independent performance is also affected in daily life by fine motor function and gross motor function impaired. The function of the hand, expressed by the fine motor function, is essential to handle objects in daily life. The bimanual fine motor function classification system, BFMF, was developed for the hand function Evaluation according to the severity of the involvement in children with cerebral palsy [4].
Several studies have revealed that the lack of hand function development causes a decrease in sensory information, voluntary game, experience and learning ability. That is, it leads to a functional decline in daily life and restrictions in social participation $[5,6]$. The decrease in fine motor function is frequently observed in children with cerebral palsy. As such, fine motor function should be considered along with gross motor function to better understand all domains of children's daily live. Children with cerebral palsy show a great variation of limitations in the use of the hands, being from difficulties in the intramanual handling or more severe impediments to produce an impossible grasp or support of an object $[7,8]$.

The international classification systems of hand function provide common terminology and descriptions that can improve the understanding of diversity in hand limitations in children with cerebral palsy [9-11]. They can also help identify the most appropriate intervention for children with different levels of performance in their hand function. 
The BFMF classification system is a five-level ordinal scale, in which level I describes the best performance and level $\mathrm{V}$ the most limited function $\neg 3$. It was developed to classify the ability of children with cerebral palsy to use both hands together when handling objects. It can be assessed from the observation of the bimanual performance Child in combination with the parent's report on the usual performance.

Each level of qualification along with the description of the severity of the deficiency contains one or two sets of criteria with which to assess whether the child has a motor abnormality of the upper limb predominantly unilateral or asymmetric (instead of bilateral). For example, the criteria described in level I, IIa and IIIa describe a unilateral impediment; the criteria in levels IIIb and IVb describe an asymmetric deterioration; and the criteria for level IIb, IVa and V describe the bimanual impact. The stability of BFMF over time indicates that the classification levels are stable for most children [12].

Classification of hand function in children with cerebral palsy can serve several purposes [13]:

- Describe the common characteristics of the function of the hand in a coherent and meaningful way.

- Improve communication between professionals and parents.

- Help to understand and identify the needed for intervention and support for children who are classified at different levels of functioning.

The BFMF 2 classification system is a necessary complement to classify the manual function in conjunction with the Manual Ability classification system, MACS [9], which already describes the fine motor capacity of the two hands separately. In this way the specific needed for intervention and the necessary support of each of the limbs can be described in greater detail.

Due to the present incidence of infantile cerebral palsy and the impact on daily life of the impairment of hand function, the transcultural adaptation to Spanish [14-16] of the bimanual fine motor function classification System, BFMF is of great needed.

The objective of this study was to translate and validate crossculturally the BFMF 2 for the Spanish population, as an instrument for the classification of bimanual fine motor function in children with 3 to 18 years old, diagnosed with infantile cerebral palsy.

\section{Materials and Methods}

\section{Instrument}

The bimanual fine motor function classification system, BFMF, was developed by Beckung and Hagberg in 2002 [3]. This first version was not very clear in understanding the differences between the five levels described. It was developed with the objective of maintaining correspondence with the levels of the gross motor function classification system, GMFCS (Table 1).

Due to the needed for a clarification of the five levels of the classification system, in 2016 Elvrum, et al. [10]. They suggested several changes for a better understanding of the levels. The first step was to develop a revised and easy-to-use the BFMF edition, later called BFMF 2, adding more precise descriptions of levels (IV) and sub-levels (a) and (b) of fine motor function to facilitate understanding and applicability of the classification system. The wording and content of the different levels of the original BFMF were discussed and evaluated by a pediatrician, a pediatric neurologist, a physiotherapist and two occupational therapists [10].

Table 1: Classification levels of gross motor function and fine motor function in Imfantil cerebral palsy. ICP.

\begin{tabular}{|c|c|}
\hline Gross Motor Function Classification System GMFCS & Bimanual Fine Motor Function BFMF2 \\
\hline $\begin{array}{l}\text { Level I. Walk without restrictions. Restrictions on more advanced gross } \\
\text { motor skills }\end{array}$ & $\begin{array}{l}\text { Level I. A hand manipulates without restrictions. The other hand } \\
\text { manipulates without restrictions or restrictions on the most advanced fine } \\
\text { motor skills. }\end{array}$ \\
\hline $\begin{array}{l}\text { Level II. Walk without restrictions. Limitations for walking outdoors and } \\
\text { in the community. }\end{array}$ & $\begin{array}{l}\text { Level II (a) A hand manipulates without restrictions. The other hand only } \\
\text { ability to grasp or hold. } \\
\text { (b) both hands: limitations on the most advanced fine motor skills. }\end{array}$ \\
\hline $\begin{array}{l}\text { Level IV: Automobile with limitations, children are transported or use } \\
\text { motorized mobile outside and the community. }\end{array}$ & $\begin{array}{l}\text { Level IV: (a) both hands only ability to grasp. (b) one hand only ability to } \\
\text { grasp and the other hand only ability to hold or worse. }\end{array}$ \\
\hline $\begin{array}{l}\text { Level V: Automobile is severely limited even with the help of assisted } \\
\text { technology. }\end{array}$ & Level V: Both hands only ability to hold or worse. \\
\hline
\end{tabular}

The BFMF 2 clearly defines the four main terms "without restriction" "Restriction in advanced fine motor skills", "can hold and hold, not intramanual manipulation" and "could hold"), which are used to distinguish the five classifications of the levels that can be seen in Table 2. In addition, explanatory figures were created for each of the five classification levels that were constructed to describe the various combinations of the function of each hand.
The revised BFMF 2 has excellent intra and interobserver reliability. Thus, the use of BFMF 2 can provide valuable information about the ability to use each hand separately to hold, grasp and handle objects in children with cerebral palsy. The classification levels could be determined from short video recordings of three fine motor tasks (grasping, holding a handling: pencil, cereal, bucket). This indicates that the BFMF 2 can be an efficient instrument 
for research, as well as for clinical use, giving easily accessible information regarding the bimanual fine motor function of a child diagnosed with cerebral palsy.

Table 2: Explanatory terms of the hand functioning in each classification level of the "BFMF 2".

\begin{tabular}{l} 
Without restrictions \\
Intra-manual manipulation: with Speed and precision. Grasps all types of \\
objects with speed and precision \\
\hline Can hold and hold, without intramanual manipulation. \\
There is no intramanual manipulation, \\
The child can manipulate against the table or the body. Grasps certain \\
objects from the table and other objects from an adapted position, \\
reducing speed and accuracy. \\
\hline Restriction in advanced fine motor skills \\
Intra-manual manipulation: speed and precision reduction. Grasps \\
objects from the table; Speed and precision reduction. \\
\hline Could hold \\
There is no manipulation of objects, the child cannot grasp objects from \\
the table, could grasp some objects from an adapted position, could hold \\
an object placed in the hand.
\end{tabular}

Translation to Spanish and retrotraduction to the original language

The methodology of this work follows the psychometric parameters of transcultural validation of the measurement scales. First, authorization was requested from the authors of the BFMF 2 scale, belonging to the BFMF team, whose representative was Kate Himmelmann, who indicated their approval to the cross-cultural validation of the classification system and showed the guidelines to follow:

Translation of the original version in English to Spanish: The authors of the revised bimanual fine motor function classification system BFMF 2, sent the original version in English. So, the first step in the validation process was to write two translations of the original, into Spanish, by two different translators; of these two translations, a single version was obtained.

Subsequently, a meeting was held with 5 experts in the management of people with infantile cerebral palsy and specialists in the functionality of the upper limb in pediatrics to obtain and agree on a definitive translation.

The Spanish version must be culturally equivalent to the initial version in English, based on previously established criteria [16] of equivalence: a) semantics: equivalence in the meaning of words, sometimes being necessary grammatical alterations in the construction of some sentences ; b) idiomatic: equivalence in colloquial expressions, which sometimes cannot be translated literally; c) of the experiences: equivalence in terms of the customs of each culture and d) conceptual: equivalence of the validity of the concept, since some items can be semantically equivalent but not conceptually.

Backtranslation from the Spanish version to English: Once this definitive version was obtained in Spanish, two backtranslations were made by two different translators, from Spanish to the original language, English, until obtaining a single English version, which would be sent to the authors of BFMF 2 .

Modifications and corrections of the Spanish version back translated into English: Once the single English version of the Spanish back-translation was obtained, it was sent to the authors, who analyzed it and gave its approval of it.

Dissemination of the correct Spanish version: Created the single correct version in Spanish and passed to the format of the BFMF 2 classification system, we acquired the permission to be able to disseminate the Spanish version within the Spanish-speaking population and the possibility of publishing the transcultural adaptation.

\section{Results and Discussion}

Once the Spanish translation of the original version and the back translation into English were obtained, the members representing the team of experts evaluated the equivalence of the 5 levels of the classification system. The results obtained were that the 5 levels are considered $100 \%$ conceptually equivalent to the original version of the instrument, being literal.

No different levels were obtained (in which the meaning of it changed) nor was it necessary to add or exclude any level of the scale, as well as change its location, given the hierarchical structure of it. Thus, we obtained a unique version in Spanish, whose back translation to the original language, English was approved by the BFMF 2 classification System authors.

The evaluation of the fine manual function of a child must be carried out using classification systems that provide great validity and reliability. The needed to use the same measurement tools, scales that allow us to express the clinical results consistently and objectively throughout the clinical intervention is of great importance. In addition, it is important to use the same methods of measurement universally in order to make cross-cultural comparisons and international research studies.

The evaluation of bimanual fine motor function in ICP is essential for a classification of functioning and intervention during the school stage. The BFMF 2 classification system has an excellent inter and intra-rater reliability (0.9) [13] and its administration can be carried out in 5 minutes, it is relatively easy to determine the level of classification, while being useful for multiple ranges of ages and functional abilities.

The BFMF 2 has been used in various investigations together with the manual ability classification system, MACS [9], to complete the fine hand ability of both upper limbs in infantile cerebral palsy, in conjunction with the gross motor function classification System, GMFCS [3] to establish a correlation between both levels through the limitations and restrictions according to the activity and participation of the child in the usual environment, also used in the follow-up during 15 years of the hand function after a traumatic brain injury [18]. 
It is a classification system that despite being used as a tool for assessing bimanual fine functioning in ICP prior to an intervention, is not sensitive to changes, since the levels described have a wide range of variation and the changes can occur within the same level without modifying the hand ability level. They are stable levels in time.

Being an observational measure, the BFMF 2 requires the patient to demonstrate diverse fine motor abilities with both hands through three concepts: grasp, hold and handle, so a series of elements are used to appreciate the level and is completed with the contributions of the family and educational personal, according to their natural behavior within their usual environment. Your administration can take approximately 5 minutes.

The methodology used in this phase of the transcultural validation of the BFMF 2 to the Spanish population includes a translation-back-translation procedure allowing that the Spanish version is an instrument conceptually comparable to the original. For this, the methodology proposed by Guillemin, et al. [14-16] has been followed, widely used in the translation processes of Classification system. The presence of two independent bilingual translators allows us to detect errors and divergent interpretations of the classification levels described and create a single Spanish version, performing the same process with the back translation of the document by two other independent translators and without knowing each other, which provides greater quality to the information obtained in the created versi The committee of experts was based on structured criteria to resolve existing discrepancies, being able to modify, eliminate or add new terms to always maintain an equivalence between the two versions. During the meetings of the expert group, no significant semantic problems were found in the translation of the scale into Spanish, and it is not necessary to change the meaning of any term within each level. Most of the changes made consisted in the modification of expressions with difficult literal translation to our language, but always maintaining the equivalence between the two versions $[19,20]$.

No validation of the scale has been found in a language other than Spanish, so our results cannot be compared with those of other researchers.

However, being well-defined expressions and operating states with the same meaning for different cultures, it is to be assumed that their semantic equivalence would not be altered when translated into another language.

\section{Conclusion}

The Spanish version of this bimanual fine motor function classification system BFMF 2 for infant cerebral palsy in the school stage allows to define in a more exhaustive way the handling with both hands and to obtain a classification of it through a level that represents their best bimanual fine ability.

\section{Acknowledgement}

Thank the entire BFM team for their dedication and grant permission for cultural validation.

\section{Conflict of Interest}

There is not conflict of interest by the author.

\section{References}

1. Stanley F, Blair E, Alberman E (2000) Cerebral palsies. Epidemiology and causal pathways. Clinics in developmental medicine. N.151. Mac Keith Press, London.

2. Ferrari A, Sghedoni A, Alboresi S, Pedroni E, Lombardi F (2014) New definitions of 6 clinical signs of perceptual disorder in children with cerebral palsy: an observational study through reliability measures. Eur J Phys Rehabil Med 50(6): 709-716.

3. Beckung E, Hagberg G (2002) Neuroimpairments, activity limitations, and participation restrictions in children with cerebral palsy. Developmental Medicine \& Child Neurology 44(5): 309-316.

4. Arnould C, Penta M, Thonnard JL (2007) Hand impairments and their relationship with manual ability in children with cerebral palsy. J Rehabil Med 39(9): 708-714.

5. Holsbeeke L, Ketelaar M, Schoemaker MM, Gorter JW (2009) Capacity, capability, and performance: different constructs or three of a kind? Arch Phys Med Rehabil 90(5): 849-855.

6. Ostensjo S, Carlberg EB, Vollestad NK (2004) Motor impairments in young children with cerebral palsy: relationship to gross motor function and everyday activities. Dev Med Child Neurol 46(9): 580-589.

7. Arner M, Eliasson AC, Nicklasson S, Sommerstein K, Hagglund G (2008) Hand function in cerebral palsy. Report of 367 children in a populationbased longitudinal health care program. Journal of Hand Surgery American 33(8): 1337-1347.

8. Krumlinde Sundholm L (2008) Choosing and using assessments of hand function. In AC Eliasson, PA Burtner (Eds.), Improving hand function in children with cerebral palsy: Theory, evidence and intervention, London 178: 176-97.

9. Eliasson AC, Krumlinde Sundholm L, Rosblad B, Beckung E, Arner M, et al. (2006) The manual ability classification system (MACS) for children with cerebral palsy: scale development and evidence of validity and reliability. Developmental Medicine \& Child Neurology 48(7): 549-554.

10. Elvrum AK, Andersen GL, Himmelmann K, Beckung E, Ohrvall AM, et al. (2016) Bimanual fine motor function (BFMF) classification in children with cerebral palsy: Aspects of construct and content validity. Physical \& Occupational Therapy in Pediatrics 36(1): 1-16

11. Himmelmann K, Beckung E, Hagberg G, Uvebrant P (2006) Gross and fine motor function and accompanying impairments in cerebral palsy. Developmental Medicine \& Child Neurology 48(6): 417-423.

12. Nystrand M, Beckung E, Dickinson H, Colver A (2014) Stability of motor function and associated impairments between childhood and adolescence in young people with cerebral palsy in Europe. Developmental Medicine \& Child Neurology 56(9): 833-838.

13. Elvrum AG, Beckung E, Sæther R, Lydersen S, Vik T, et al. (2017) Bimanual Capacity of Children with Cerebral Palsy: Intra- and Interrater Reliability of a Revised Edition of the Bimanual Fine Motor Function Classification. Phys Occup Ther Pediatr 37(3): 239-251.

14. Guillemin F, Bombardier C, Beaton D (1993) Cross-cultural adaptation of health-related quality of life measures: Literature review and proposed guidelines. J Clin Epidemiol 46(12): 1417-1432.

15. Esteve Vives J, Batlle E, Reig A, Alonso Caballero J (1991) Transcultural adaptation of a health questionnaire. Revolver Esp Rheumatol 18: 254257.

16. Robles Pérez De Azpillaga, M Rodríguez Piñero Durán, MJ Zarco Periñán, B Rendón Fernández, C Mesa López, et al. (2009) Spanish version of the Gross Motor Function Measure (GMFM): the initial phase of its transcultural adaptation. Rehabilitation (Madr) 43(5): 197-203.

17. Badia X (1995) On the transcultural adaptation of health-related quality of life measures for use in Spain. Med Clin (Barc). 105: 56-58. 
18. Ahlander AC, Persson M, Emanuelson I (2013) Fifteen-year follow-up of upper limb function in children with moderate to severe traumatic brain injury. J Rehabil Med 45(8): 815-819.

19. Anna Febrer, Meritxell Vigo, Joaquín Fagoaga, Julita Medina Cantillo, Natalia Rodríguez, et al. (2011) Hammersmith functional assessment scale for children with spinal muscular atrophy. Validation of the Spanish version. Rev Neurol 53(11): 657-663.
20. Fagoaga J, Girabent Farrés M, Bagur Calafat C, Febrer A, Steffensen BF (2013) [Translation and validation of the Egen Klassifikation scale for the Spanish population: functional assessment for non-ambulatory individuals with Duchenne's muscular dystrophy and spinal muscular atrophy]. Rev Neurol 56(11): 555-561.

Complementary material 1: Bimanual Fine Motor Function Classification System, BFMF 2. Original Version 2.0

I

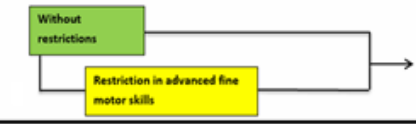

II
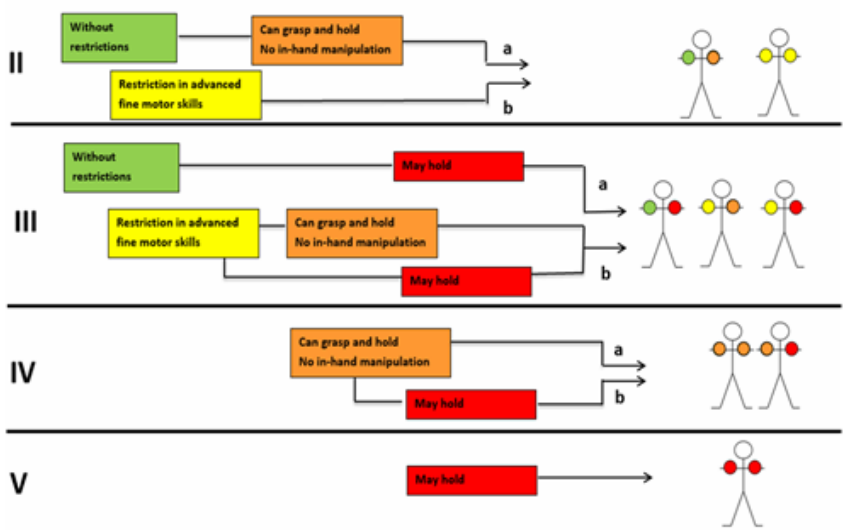

\section{References}

Beckung E, Hagberg G (2002) Neuroimpairments, activity limitations, and participation restrictions in children with cerebral palsy. Dev Med Child Neurol 44.(5): 309-316.

Elvrum AKG, Andersen GL, Himmelmann K, Beckung E, Öhrvall AM, et al. (2016) Bimanual Fine Motor Function (BFMF) Classification in Children with Cerebral Palsy: Aspects of Construct and ContentValidity.Phys Occup TherPediatr 36(1): 1-16

Elvrum AKG, Beckung E, Sæether R, Lydersen S, Vik T, et al. (2016) Bimanual capacity of children with cerebralpalsy:Intra-andinter-raterreliability ofarevisededition ofthe BimanualFineMotor Functionclassification.Phys 0ccupTherPediatr 37(3):239-251.

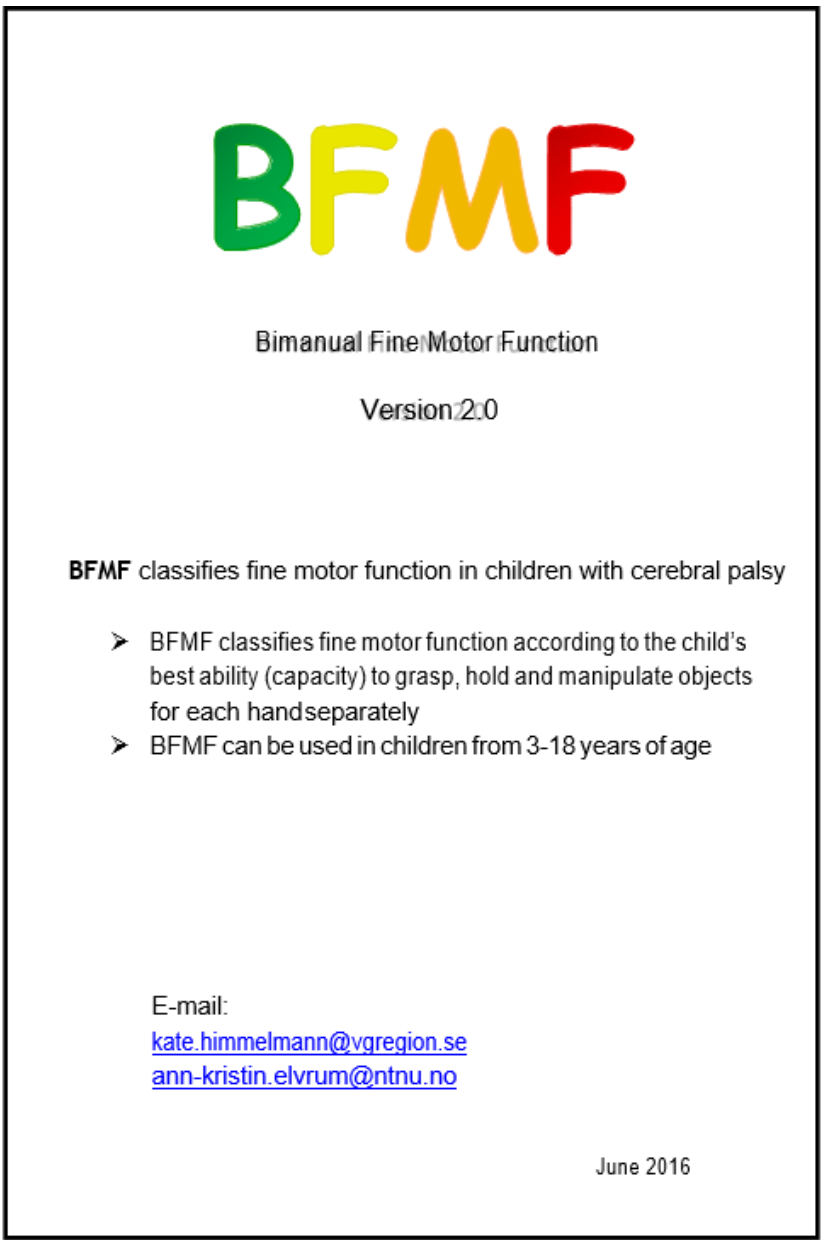




\section{Information for users}

The Bimanual Fine MotorFunction (BFMF) classifies finemotorfunction in children withcerebralpalsy.BFMFdescribesfivelevelsoffinemotorfunction and covers the entirespectrum of limitations in finemotorfunction thatmaybe foundamongchildrenwithvariouscerebralpalsysub-types.Levellincludes children with minorlimitations and levels IV-Vdescribe children with severe functional limitations.

BFMFcanbeusedforchildrenaged 3-18years, butabilitytoperformin-handmanipulation must be considered in relation to the child's age. Naturally there is a difference in how a three-year old should be able to manipulate objects, compared with a teenager. For theyoungest children the ability to rotate an objectin the fingerscannotbe expected, butthe child maytransformanobject from the fingers to the palm. If ability to perform in-hand manipulation cannot be established for the youngest children, the BFMF level should be determined according to ability to grasp.

Thefivelevelsin BFMF formanordinalscale, whichmeansthatthelevelsare 'ordered'butdifferencesbetweenlevelsarenotnecessarilyequal,and each level includeschildrenwithrelativelyvariedfunction.Itisthereforeunlikelythat $B F M F$ is sensitive to changes after an intervention.

The new BFMFversion 2.0 offers explanatory figures and precise description sof the finemotorfunctionlevels to facilitate the use of the classification system.

\section{Without restriction}

In-hand-manipulation: with speed and precision Grasps all kind of objects with speed and precision

Can grasp and hold, no in-hand manipulation No in-hand manipulation, may manipulateagainsttableorbody Grasps selected objects from the table and otherobjects from an adapted position, reducedspeed and precision

\section{BFMF version 2.0}

Level I

One hand: manipulates without restrictions. The other hand:manipulateswithoutrestrictionsor limitationsinmore advanced finemotorskills

\section{Level II}

a) Onehand:manipulateswithoutrestrictions. The other hand: only ability to grasp or hold

b) Both hands: limitations in more advanced fine motor skills

\section{Level III}

a) Onehand:manipulateswithoutrestrictions. The other hand no functional ability

b) Onehand:limitationsinmoreadvancedfine motorskills. Theotherhand:onlyabilitytograsp or worse

\section{Level IV}

a) Both hands: only ability to grasp

b) One hand: only ability to grasp. The other fine motorskills
In-hand manipulation: reduced speed and precision Grasps objects from table; reduced speed and precision hand: only ability to hold or worse

\section{May hold}

No manipulation of objects Cannot grasp objects from the table may grasp a few objects from an adapted position May hold object placed in hand

\begin{tabular}{|l|}
\hline hand: only ability to hold or worse \\
\hline $\begin{array}{l}\text { Level } \mathbf{~} \\
\text { Both hands: only ability to hold or worse }\end{array}$
\end{tabular}


Complementary material 2: Bimanual Fine Motor Function Classification System, BFMF 2. Spanish Version 2.0
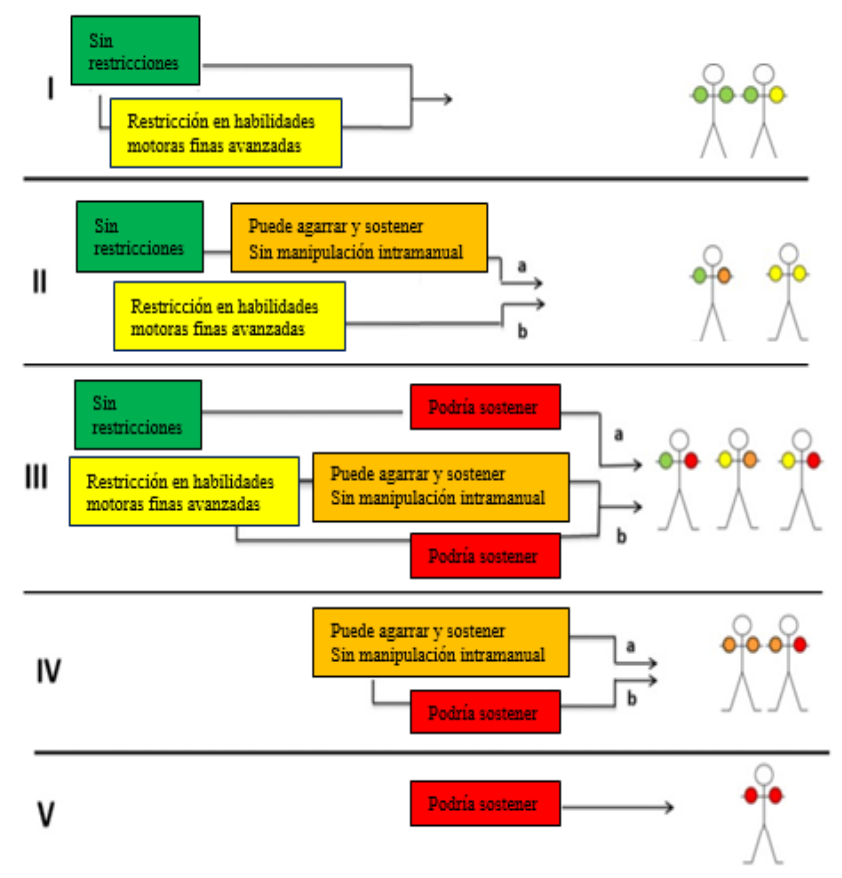

\section{Referencias:}

Beckung E, Hagberg G (2002) Neuroimpairments, activity limitations, and participation restrictions in children with cerebral palsy. Dev Med Child Neurol 44(5): 309-316.

Elvrum AKG, Andersen GL, Himmelmann K, Beckung E, Öhrvall AM, et al. (2016) Bimanual Fine Motor Function (BFMF) Classification in Children with Cerebral Palsy: Aspects of Construct and Content Validity. Phys Occup Ther Pediatr 36(1): 1-16.

Elvrum AKG, Beckung E, Sæether R, Lydersen S, Vik T, et al. (2016) Bimanual capacity of children with cerebral palsy: Intra- and inter-rater reliability of a revised edition of the Bimanual Fine Motor Function classification. Phys Occup Ther Pediatr 37(3):239-251.

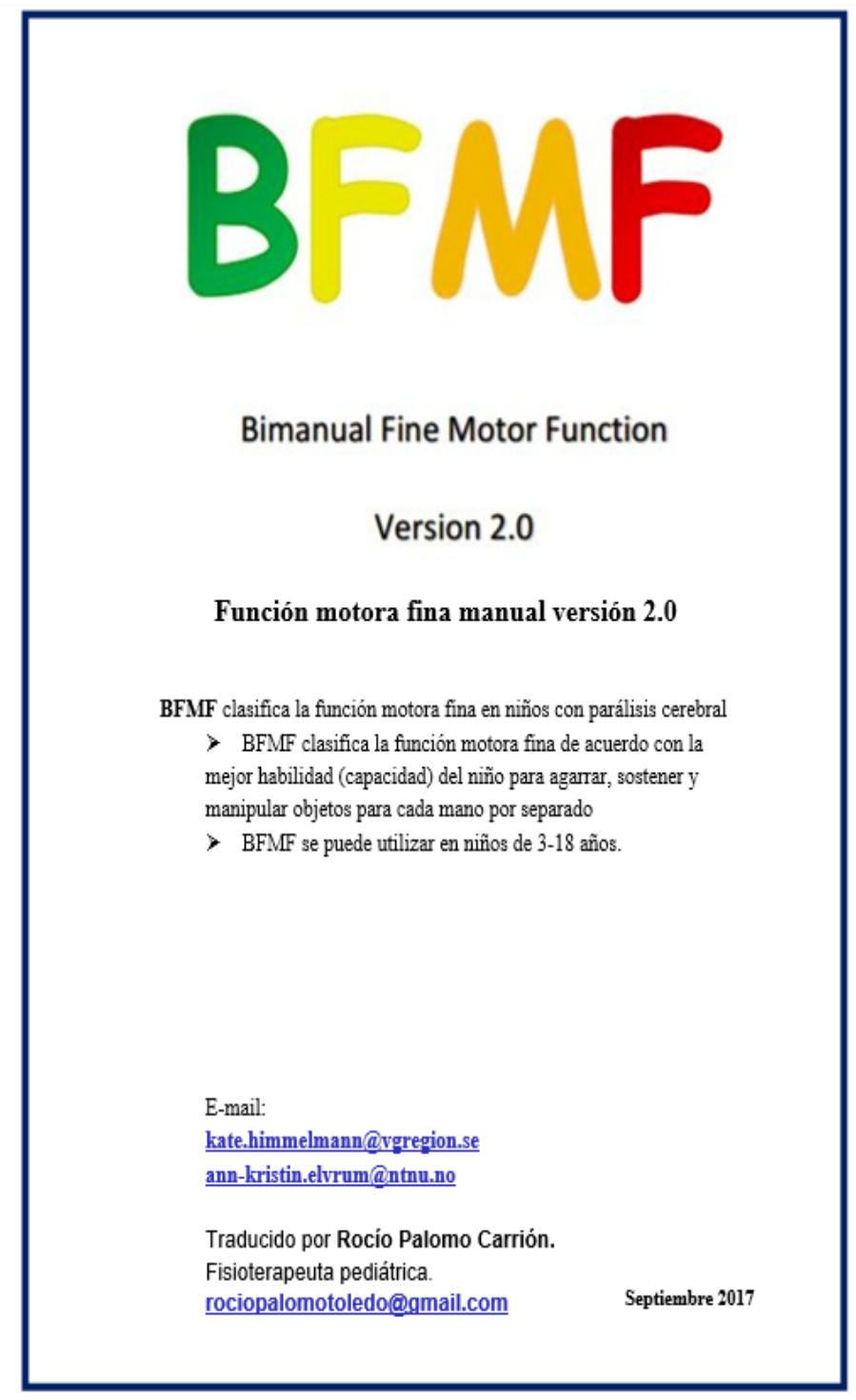




\section{Información para usuarios}

La Función Motora Fina Bimanual (BFMF) clasifica la función motora fina en niños con parálisis cerebral. BFMF describe cinco niveles de función motora fina y cubre todo el espectro de limitaciones en la función motora fina que podrían ser encontradas entre niños con varios subtipos de parálisis cerebral. El nivel I incluye a los niños con limitaciones menores y los niveles IV-V describen a los niños con limitaciones funcionales severas.

BFMF se puede utilizar para niños de 3-18 años, pero se debe considerar la habilidad de realizar una manipulación intramanual en relación con la edad del niño. Naturalmente hay una diferencia en cómo un niño de tres años debería ser capaz de Naturalmente hay una diferencia en cómo un niño de tres años debería ser capaz de
manipular objetos, en comparación con un adolescente. Para los niños más pequeños, no se puede esperar la habilidad de rotar un objeto en los dedos, pero el niño podría mover un objeto desde los dedos hasta la palma. Si no se puede establecer la habilidad para realizar una manipulación intramanual en los niños más pequeños, el nivel de BFMF debería ser determinado según la habilidad para agarrar.

Los cinco niveles en BFMF forman una escala ordinal, lo que significa que los niveles son "ordenados", pero las diferencias entre los niveles no son necesariamente iguales, y cada nivel incluye niños con funciones relativamente variadas. Por lo tanto, es improbable que BFMF sea sensible a los cambios después de una intervención.

La nueva versión BFMF 2.0 ofrece figuras explicativas y descripciones precisas de los niveles de función motora fina para facilitar el uso del sistema de clasificación.

\section{Sin Restricción}

Manipulación intramanual: con Velocidad y precisión

Agarra todo tipo de objetos con velocidad y precisión

Puede agarrar y sostener, sin manipulación intramanual

No hay manipulación intramanual, puede manipular contra la mesa o el cuerpo.

Agarra determinados objetos desde la mesa y otros objetos desde una posición adaptada, reducción de la velocidad y precisión.

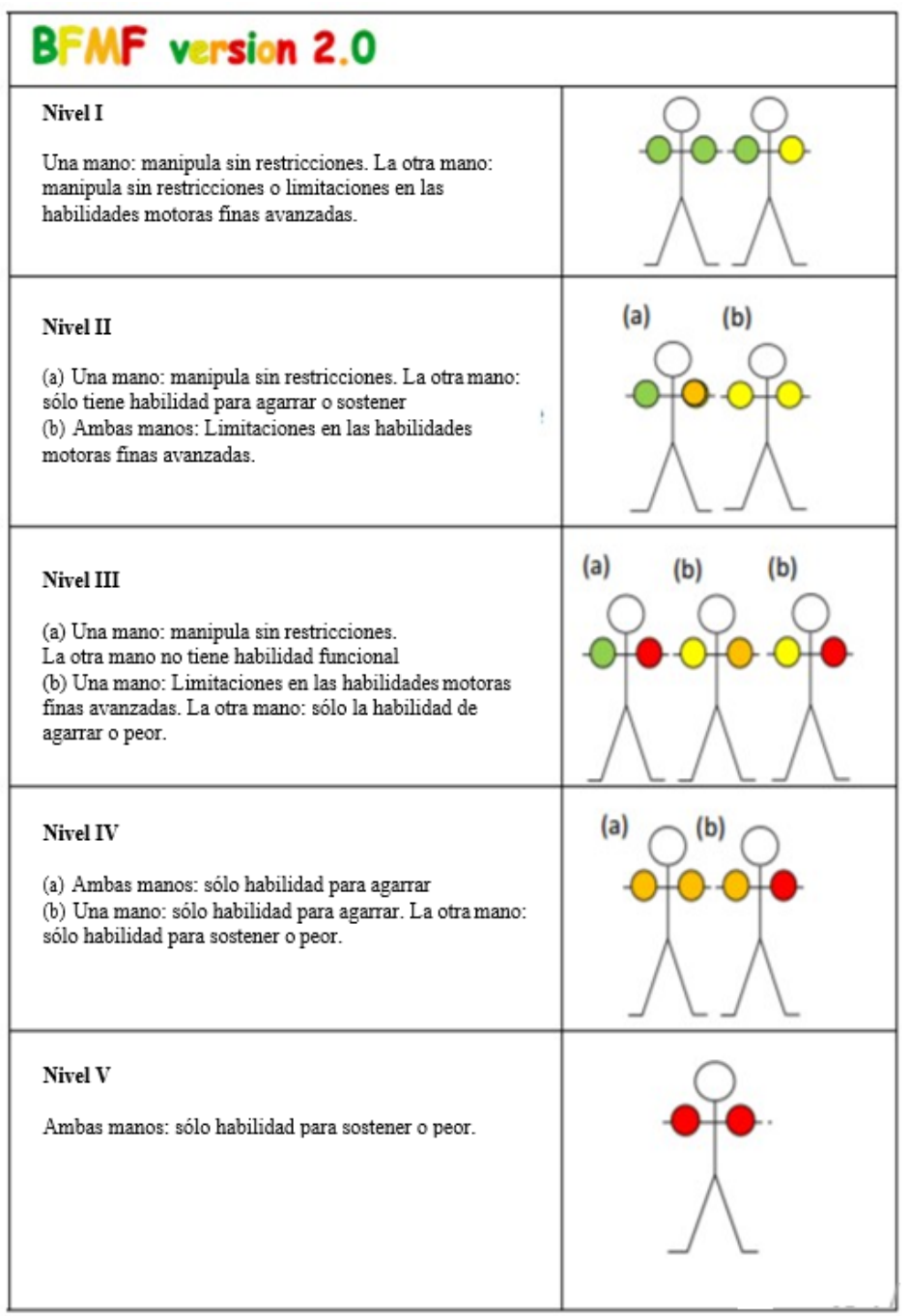

